Why so much on psychiatric reform in America? How does it relate to the book's purpose? The choice may appear arbitrary.

Two rather more serious problems are fairness and consistency. Like everyone else, Schwartz has his preferred theorists and they are those who emphasize the external over the internal; for instance, John Bowlby, Donald Winnicott and Heinz Kohut. This seems inconsistent, in view of his description of psychoanalysis as the attempt to "understand the structure and dynamics of the inner world of the experiencing human being". In fact, the question of external and internal is not as simple as Schwartz suggests.

As for fairness, psychoanalysts have from the outset dealt with theoretical disagreements by accusing opponents of personal failings, sometimes verging on character assassination. Schwartz the scientist knows that the theory-maker's personality is irrelevant to the value of the theory, but Schwartz the polemicist cannot resist joining in the fun. Melanie Klein is in danger of emerging as a difficult woman who had some important ideas about children but paid little attention to the outside world. This fails to do justice by a long way to the depth of her ideas, for instance her formulation of the paranoid and depressive positions, which provides psychological grounds for some fundamental questions of society and politics, and their subsequent development by others. By Wilfrid Bion, for example, regarded by many as the most profound psychoanalytic thinker since Freud, but who gets just one mention - in a chapter note.

One must not be unjust to the opposition. To give one example, Joan Riviere was an early and enthusiastic supporter of Klein. She was also a rather conflicted woman and she went into analysis with Ernest Jones, himself an equivocal character, who seems to have behaved quite unprofessionally towards her. Jones finally sent her to Freud, who repaired some of the damage and wrote in forthright terms to Jones about his conduct. Schwartz mentions that Riviere translated some of Freud's papers, but fails to mention that she wrote a number of her own, including one on the clinical problems of narcissism which has become a classic. As a result she emerges as a rather neurotic lady but not as the significant figure she was.

To return to Schwartz's declared purpose, psychoanalysis does indeed have a place in twentieth-century Western tradition, and in his view it is a high destiny. This approach can easily lead to some rather large statements, such as "psychoanalysis has been charged not with participating in the glory of the Industrial Revolution but with clearing up the mess it left behind". One can nod in agreement, or one can take it with a pinch of salt, but this sort of thing is risky, as another example, which may raise some eyebrows this side of the Atlantic, shows - "He went to
Cambridge in 1925, then at the height of its fame in natural sciences".

This could have been a truly well-argued book if Schwartz the scientist had kept a better hold on the other Schwartz. As it is, anyone reading it will certainly learn something about psychoanalysis, and may be stimulated to read further. There is still a book to be written about the development of psychoanalytic thinking and practice which steers clear of the personal. It will be longer and will not be such a racy read.

Jane Kitto is an analytical psychotherapist and is at 2 The Park, London N6 4EU, UK.

\section{Dogs, telepathy and quantum mechanics}

\section{Dogs That Know When Their Owners Are Coming Home - And Other Unexplained Powers of Animals \\ by Rupert Sheldrake \\ Crown: 1999. 323 pp. £16.99, \$25 \\ John Maddox}

Rupert Sheldrake is steadfastly incorrigible in the particular sense that he persists in error. That is the chief import of his eighth and latest book. Its main message is that animals, especially dogs, use telepathy in routine communication.

The interest of this case is that the author was a regular scientist, with a Cambridge $\mathrm{PhD}$ in biochemistry, until he chose pursuits that stand in relation to science as does alternative medicine to medicine proper. Some readers with long memories may recall that, when Sheldrake's first book appeared in 1981, it was referred to in an injudicious leading article in this journal (Nature 293, $245 ; 1981)$ under the title "A book for burning?" (where the question-mark was intended as part of the title). The text that followed went on to declare roundly that "even bad books should not be burned", and concluded that the book "should not be burned... but put firmly in its place among the literature of intellectual aberration".

The publicists for Sheldrake's publishers were nevertheless delighted with the piece, using it to suggest that the Establishment (Nature) was again up to its old trick of suppressing uncomfortable truths. Many years later, Sheldrake confided to my wife that his children routinely prayed for the soul of the editor of Nature, believing that such a wicked person could only come to a bad end.

The motif of the first book, which formed its title, A New Science of Life: The Hypothesis of Formative Causation, runs through all the later volumes in this distinctive oeuvre. Sheldrake believes that the form or shape of all things, animate or otherwise, is acquired through the influence of "morphic fields" in a process called "formative causation". Moreover, morphic fields evolve in the course of time, ensuring that when a crystal of copper sulphate or a daffodil first takes on a particular habit, the morphic field ensures that all later crystals of copper sulphate (or all daffodils) follow the same pattern.

In Dogs That Know ..., morphic fields have an appendix to themselves, but also frequently recur in the body of the text. In a new twist, Sheldrake cautiously advances the idea that his morphic fields may share with those of quantum mechanics some of the properties of non-locality which offer the chance of making even faster computers some time next century.

Even Sheldrake's fiercest critics will applaud his consistency. The purported role of morphic fields on the shapes of objects in the real world has hardly changed since 1981. It is no less - and no more - than it was then. The idea is borrowed from classical embryology, where a gradient of the concentration of some chemical (such as the protein product of a Hox gene) is supposed to regulate the development of part of an organism's body, and is sometimes referred to as a "morphogenetic field". But morphic fields are evidently all-pervading. No corner of space can be free from them, for then copper sulphate crystals (or daffodils) would acquire different shapes in different locations.

Similarly, Sheldrake's opinion of science has not changed. He speaks of the gulf between "personal experience and the theory that living organisms ... are merely soulless automata", and declares that his experience has made him a holist.

So what is new in this latest book? As Sheldrake describes it, causative formation is no longer merely a hypothesis, but a research programme, complete with the now-standard perquisites of a database and a website (www.Sheldrake.org). And the data? A vast and growing collection of information about incidents involving domesticated animals in interaction with people, or sometimes other animals. The title of the book refers to the copious collections of records, written by people responsible for dogs and, less frequently, cats, describing the pets' capacity to anticipate the arrival home (from work or from a journey) of a second human member of the household. Sometimes the dogs react, not when the second party is leaving the office, say, but when he or she has decided that the time has come to leave.

As an observational programme, none of this is simple. How does a dog signal its anticipation of the homecomer? By waiting at the garden gate, or inside the front door of the house, wagging its tail all the while or showing other signs of excitement. There is the case of a male dog called Jaytee, from a small town in Greater Manchester, who was closely observed and then videotaped in the course 
of exercising anticipation of its carer's remote movements. Anticipation was signalled by the dog sitting at a window from which the outside world could be observed. The dog sat in the window on 55 per cent of the occasions when the return journey was under way, but only 5 per cent of the time when the carer (called Pam) was absent. For the videotaped observations, the timing of Pam's return was determined by a third party (using a cellular telephone) at random times: this, Sheldrake says, is when the dog's behaviour most clearly showed the knack of knowing when Pam had decided to return but had not yet embarked on the journey home.

By conceding that the data gathered during these observations are statistically significant, one does not sign up for Sheldrake's interpretation that the underlying mechanism is dog-Homo telepathy. Too many variables are uncontrolled. Did the accuracy of anticipation vary with the length of time elapsed since Pam's departure (suggesting that the dog used its sense of the passage of time to signal its sense of when return was due)? Were there people in the room with the dog (allowing them to communicate somehow with the eager waiter)? And while Jaytee appears to have been chosen for videotaping as a result of his acumen in earlier trials, does not the interpretation of his behaviour require an understanding of the variability of dogs' capacity for anticipation in general? The appendix in which these details are meticulously described is not so much a log of research under way as a record of one of those sets of observations preliminary to the design of properly controlled observations.

The remainder of the main text of this book, meanwhile, is curiously boring. It consists mostly of accounts, running to a few pages at the most, of how horses have been able to find their way home with an injured rider on their back, how cats have cried at the remote death of a human with whom they have been familiar, how dogs have howled when members of the family with which they live have been killed in action in some distant war, and even how people have been taken sick in sympathy with distant injured pets. Especially because people's fondness for their pets often takes the form of projecting onto them human or even superhuman perceptiveness, even more than 1,000 records on the Sheldrake website do not prove telepathy.

I doubt that Sheldrake will take the point. He makes plain his distaste for what he calls orthodox science, which is "all too often equated with a narrow-minded dogmatism that seeks to deny or debunk whatever does not fit in with the mechanistic view of the world". He is habitually courteous and cheerful, but holists of his ilk would not dream of letting controls get in the way of revealed truth.

John Maddox is at 9 Pitt Street, London W8 4NX, UK.

\section{Eccentricities of an everyday substance}

\section{$\mathrm{H}_{2} \mathrm{O}$ : A Biography of Water}

by Philip Ball

Weidenfeld \& Nicolson: 1999. 387 pp. $\mathfrak{E} 17.99$

\section{Frank H. Stillinger}

Linking human perceptions of water in mythology, cosmology, politics, literature and the physical and biological sciences (and pseudosciences) may seem to be an idiosyncratic objective. Yet that is just what Philip Ball, until recently a senior editor at Nature, has undertaken. With the possible exception of gold, there can be no other substance for which one could write such an engaging account of the profound historical influence exerted on this wide range of subjects. The author's panoramic knowledge, conveyed through a clear and often delightful writing style, makes attractive reading for a technically literate, but not necessarily expert, audience.

The narrative begins with the Big Bang and the subsequent expansion of the Universe that, in due course, produced the elements and chemical compounds, and supplied the early Earth with a chemical and physical ambience conducive to the spontaneous appearance of life. Ball traces our terrestrial geological chronology, and summarizes our present understanding of the role of continental, atmospheric and oceanic water transport in present-day meteorology. And in keeping with the burgeoning interest in planetary exploration in our Solar System, he summarizes the intriguing extraterrestrial evidence for water in both solid and liquid forms that might conceivably have spawned alternative life forms beyond Earth.

Although water has often been seen as 'unique' among liquids, labelling it as such is not especially informative, except in the most trivial sense. Nevertheless, it exhibits an impressive array of anomalies in its physical properties that might qualify it as 'eccentric'. Among these anomalies are the well-known expansion when it freezes at ordinary pressures, and the presence of a liquid-phase density maximum at $4^{\circ} \mathrm{C}$.

The author undertakes to explain, or at least to rationalize, these attributes in terms of the known structure of the water molecule, its resulting electrical asymmetry, and its propensity to engage in tetrahedral arrangements of hydrogen bonds with its own kind as neighbours. The last of these has been amusingly anthropomorphized with line drawings that should appeal to all ages: each water molecule has been rendered as a round-bodied elf whose two arms are destined to grab nearby elfin ankles. This device

^๑ 1999 Macmillan Magazines Ltd is used to introduce the reader to the structure of ordinary hexagonal ice and the forms displayed by snowflakes, and to the structures of high-pressure forms of ice.

In answering the question 'What is liquid water?' by looking at history, Ball has reflected the emergence and maturation of science itself. Beginning with the ancient Greek perception of the substance as one of the primal elements, the shifting answer has reflected specifically the rise of modern structural chemistry. But even in what one might call the 'modern' period (the past half-century, say), considerable revision has occurred to the details of how the liquid is geometrically organized by hydrogen bonding. Imaginative, but now clearly naive, pictures insisted that water should be viewed as modified

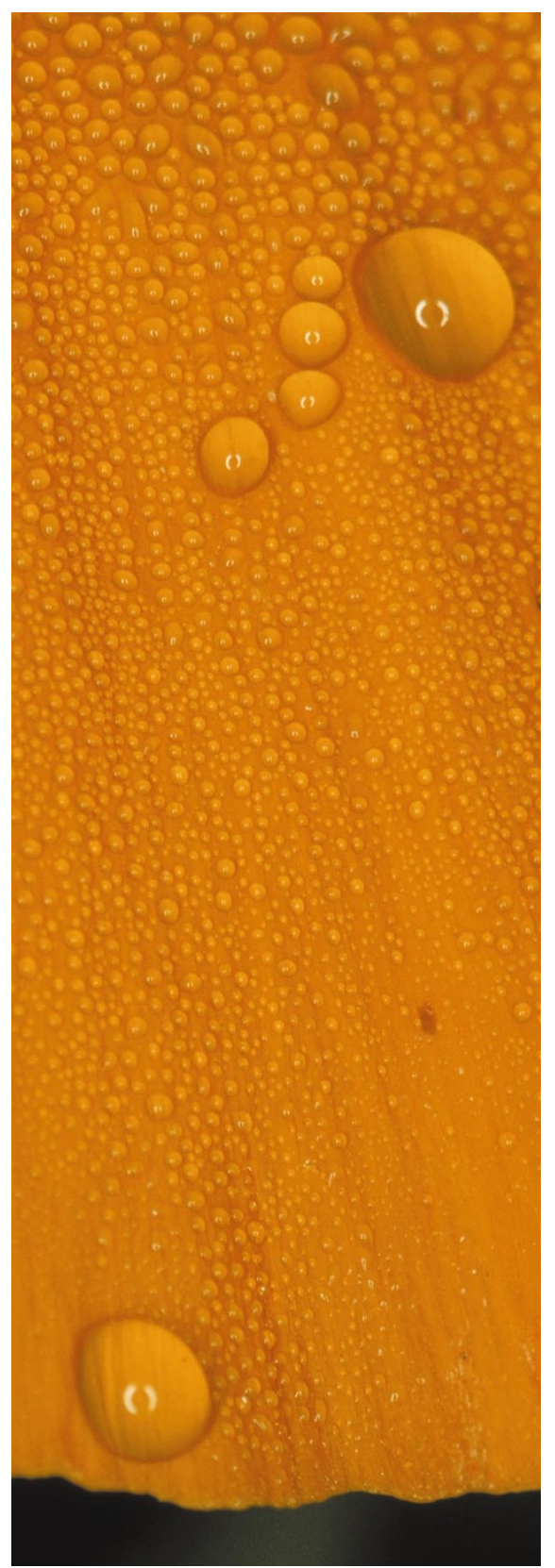

Dewdrops: a macroscopic network of molecules linked by frequent but transient hydrogen bonds. 